\title{
Usulan Perancangan Alternatif Material Handling untuk Mengurangi Risiko Keluhan Sakit dan Penentuan Waktu Istirahat Operator Pengangkat Galon (Studi Kasus Distribusi Galon Air Ke Toko Distributor "X")
}

\author{
Elty Sarvia ${ }^{1}$, Willy $^{2}$ \\ ${ }^{1,2)}$ Fakultas Teknik, Jurusan Teknik Industri, Universitas Kristen Maranatha \\ Jl. Surya Sumantri 65 Bandung 40164 \\ Email: elty.sarvia@eng.maranatha.edu,willygoals@yahoo.com
}

\begin{abstract}
ABSTRAK
Distributor X merupakan perusahaan yang bergerak dibidang distribusi air ke distributor yang tersebar di Bandung dan sekitarnya. Pekerja pengantar air galon sering mengalami keluhan sakit di beberapa bagian tubuh dan waktu istirahat yang sangat sedikit. Adapun tujuan dari penelitian ini adalah untuk menganalisis keluhan pekerja tentang rasa sakit yang dialami dengan menggunakan kuesioner Nordic Body Map, menganalisis postur tubuh pekerja dengan metode REBA (Rapid Entire Body Assessment), menganalisis risiko cedera tulang belakang yang mungkin dialami oleh pekerja ditinjau dari metode RWL (Recommended Weight Limit) dan MPL (Maximum Permissible Limit) dan mengetahui waktu istirahat yang dibutuhkan pekerja. Hasil REBA menunjukkan bahwa aktivitas 1 dan 2 berisiko menengah, sedangkan aktivitas 3 berisiko tinggi, hasil RWL dengan nilai LI menyatakan bahwa aktivitas tersebut mungkin berisiko, dan hasil MPL dengan berat beban aktual berada diantara AL dan MPL didapatkan hasil bahwa pekerjaan mengangkat galon saat ini mempunyai risiko cedera tulang belakang apabila tidak dilakukan perbaikan. Dari hasil di atas maka diperlukan adanya alat bantu berupa troli konveyor untuk memperbaiki postur tubuh pekerja saat bekerja dan mengurangi energi yang dikeluarkan pekerja sehingga pekerja dapat terhindar dari risiko cedera tulang belakang. Energi yang dikeluarkan berkurang berarti waktu istirahat yang diperlukan oleh pekerja juga tidak selama waktu istirahat secara teoritis yaitu 10 menit.
\end{abstract}

Kata kunci: REBA, RWL, MPL, waktu istirahat

\section{ABSTRACT}

Distributor $X$ is a company engaged in the distribution of water to distributors spread in Bandung and surrounding areas. Gallon water delivery' workers often experience of pain in some parts of the body and very little rest time. The purpose of this study was to analyze worker complaints about the pain experienced by using the Nordic Body Map Questionnaire, analyze the worker posture with the Rapid Entire Body Assessment (REBA) method, analyze the risk of spinal injury that may be experienced by workers using the Recommended Weight Limit (RWL) method and Maximum Permissible Limit (MPL), and find out the rest time needed by the worker. REBA results show that activities 1 and 2 are at medium risk, while activity 3 is at high risk, the results of RWL with LI values state that the activity may be risky, and the results of MPL with the weight of the actual load are between AL and MPL. Work of lifting the gallon currently has risk of spinal cord injury if no repair is performed. From the above results, a conveyor trolley is suggested to improve the worker's posture while working and reduce the energy released by workers so that workers can avoid the risk of spinal cord injury. With the decreased of energy needed, the rest time needed by the worker reduced as well.

Keywords: $R E B A, R W L, M P L$, rest period

\section{Pendahuluan}

Penelitian ini dilakukan pada proses distribusi galon air dari pabrik ke distributor-distributor khususnya ke toko distributor "X", di mana para pekerja di sini masih melakukan secara manual dan tanpa ada bantuan alat apapun dengan frekuensi angkat yang cukup tinggi. Pekerja harus mengantarkan galon ke beberapa toko distributor yang berada di beberapa lokasi yang berbeda dan dengan jarak yang jauh. Dari banyak toko distributor yang ada peneliti melakukan batasan masalah dengan meneliti hanya pengantaran galon air ke toko distributor " $X$ " karena toko distributor "X" melakukan pemesanan setiap hari dengan jumlah pemesanan 50 galon. Pengantaran hanya dilakukan satu kali dalam satu hari sehingga menyebabkan pekerja harus bekerja dengan cepat karena dikejar 
waktu dan lokasi pengantaran berbeda-beda. Cara pengangkatan yang dilakukan oleh pekerja juga tidak dengan postur yang baik dan aman dikarenakan pekerja harus mengangkat galon air dengan jalan yang cukup menanjak dan dengan posisi yang membungkuk. Survei langsung juga di lakukan untuk menganalisis kondisi aktual di lapangan dan diperoleh bahwa toko distributor " $X$ " memiliki bagian depan toko yang agak menanjak sehingga mempersulit pendistribusian galon air. Adapun masalah yang diidentifikasikan adalah bahwa keinginan pemilik distribusi galon air agar pekerja yang ada dapat bekerja secara maksimal tanpa menimbulkan efek negatif terhadap pekerja tersebut, berikut ini adalah hal-hal yang menjadi penyebab dari masalah tersebut.

1. Postur tubuh operator dalam mengangkat galon air di toko distributor " $\mathrm{X}$ " berisiko cidera.

2. Pekerja harus mengangkat galon dengan jarak yang terlalu jauh dan menanjak.

3. Waktu istirahat pekerja tidak cukup karena harus mengantar galon tidak untuk satu toko saja.

\section{Metode Penelitian}

Pada tahap awal, data-data yang diperlukan antara lain kuesioner Body Nordic Map, foto postur kerja pekerja saat melakukan pekerjaan, pengambilan data faktor pengali untuk metode RWL dan MPL serta data mengenai denyut jantung pekerja ketika mengangkat galon dengan banyak perubahan denyut jantung yang diambil setiap 1 menit. Pekerja akan diminta untuk mengisi kuesioner Body Nordic Map, yang bertujuan untuk mengetahui keluhan sakit pada bagian tubuh mana yang dirasakan oleh operator pada saat mengangkat galon air dari mobil menuju ke bagian dalam toko. Foto postur untuk menentukan sudut-sudut tubuh pekerja dengan menggunakan fitur image analysis pada software ergofellow. Penentuan sudut tubuh dilakukan pada bagian tubuh pekerja yaitu neck, trunk, legs, upper arm, lower arm dan wrist. Penentuan sudut tubuh pekerja akan membantu dalam melakukan perhitungan REBA dan MPL. Nilai REBA yang dihitung akan digunakan untuk mengetahui pekerjaan tersebut berada dalam kategori yang berbahaya atau tidak. Pada penilaian REBA terdapat 3 aktivitas yang akan dinilai yaitu pada saat pekerja mengangkat galon air dari mobil, pekerja berjalan menuju ke bagian dalam toko dan pekerja menurunkan galon. Selanjutnya adalah melakukan perhitungan nilai RWL yang merupakan rekomendasi batas beban yang dapat diangkat oleh pekerja tanpa menimbulkan cedera meskipun pekerjaan tersebut dilakukan dalam jangka waktu yang panjang. Penghitungan nilai RWL dan MPL dilakukan pada pekerjaan mengangkat galon dari mobil (Aktivitas 1) dan menurunkan galon (Aktivitas 3) saja.Untuk aktivitas berjalan ke dalam toko tidak dinilai karena tidak adanya perpindahan ketinggian benda saat pekerja memindahkan galon air. Nilai RWL yang didapat kemudian akan digunakan untuk menghitung LI. Nilai LI digunakan untuk mengetahui indeks pengangkatan apakah proses pengangkatan menimbulkan risiko cedera tulang belakang atau tidak.
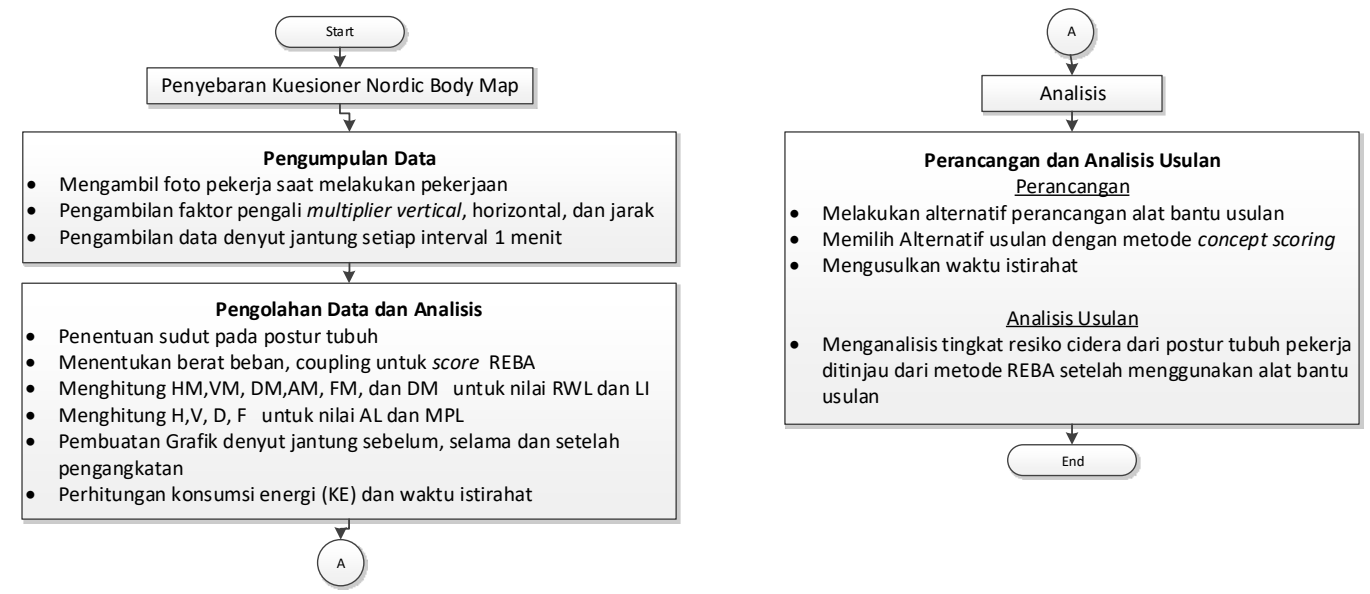

Gambar 1. Flowchart penelitian

\section{Hasil dan Pembahasan}

\section{Kuesioner Nordic Body Map}

Faktor penyebab terjadinya keluhan muskuloskeletal adalah peregangan otot yang berlebihan, aktivitas berulang, sikap kerja tidak alamiah, penyebab sekunder dan penyebab kombinasi [4]. Dari hasil kuesioner tersebut didapatkan bahwa $64 \%$ bagian tubuh pekerja tidak sakit, $29 \%$ tubuh pekerja agak sakit dan $7 \%$ bagian tubuh pekerja sakit. Adapun bagian tubuh pekerja yang agak sakit yaitu bagian bahu kiri, bahu kanan, lengan atas kiri, 
lengan atas kanan, lengan bawah kiri, lengan bawah kanan, pergelangan tangan kiri dan pergelangan tangan kanan. Bagian tubuh pekerja yang sakit yaitu bagian punggung dan pinggang.

\section{Postur Kerja dengan Metode REBA}

Penilaian faktor risiko cedera tulang belakang dilakukan dengan menggunakan metode REBA terhadap setiap aktivitas yang dilakukan oleh pekerja yaitu dari aktivitas 1 sampai aktivitas 3. Berikut adalah rangkuman hasil akhir dari final score dan tingkat risiko cedera tulang belakang yang dialami pekerja ditinjau dari metode REBA serta keputusan tindakan yang perlu dilakukan terkait dengan tingkat risiko yang telah didapatkan:

Tabel 1. Perhitungan skor REBA

\begin{tabular}{|c|c|c|c|c|c|}
\hline Aktivitas & Kegiatan & Foto Postur & Final Score & Tingkat Risiko & Keterangan \\
\hline 1 & $\begin{array}{l}\text { Mengangkat } \\
\text { galon air dari } \\
\text { mobil }\end{array}$ & & 4 & Menengah & Butuh analisis dan perbaikan segera \\
\hline 2 & $\begin{array}{l}\text { Berjalan } \\
\text { menuju bagian } \\
\text { dalam toko }\end{array}$ & & 5 & Menengah & Butuh analisis dan perbaikan segera \\
\hline 3 & $\begin{array}{l}\text { Menurunkan } \\
\text { galon air }\end{array}$ & & 8 & Tinggi & Perlu analisis dan implementasi perbaikan \\
\hline
\end{tabular}

Tingkat risiko tinggi disebabkan karena pada proses penurunan galon air dilakukan pada posisi yang sangat membungkuk yang mengakibatkan semakin tingginya risiko cedera tulang belakang yang akan dialami oleh pekerja. Posisi yang sangat membungkuk menyebabkan pekerja mengalami sakit di bagian punggung dan pinggang. Hal ini sesuai dengan keluhan pekerja yang didapat dari kuesioner Nordic Body Map.

\section{Risiko Pengangkatan dengan Metode RWL}

Tujuan dari perhitungan RWL dan LI ini adalah untuk mengetahui pengaruh beban yang dibawa oleh pekerja terhadap risiko cedera tulang belakang atau musculoskeletal disorders. Dari tabel perhitungan nilai RWL dan LI, diketahui bahwa nilai Lifting Index untuk aktivitas pengangkatan galon air tersebut mungkin berisiko. Hal ini berarti aktivitas pengangkatan galon air merupakan aktivitas yang cukup memiliki risiko cedera tulang belakang.

Tabel 2. Perhitungan RWL dan LI

\begin{tabular}{|c|c|c|c|c|c|c|c|c|c|c|c|c|}
\hline Aktivitas & Kondisi & LC & $\mathrm{Hm}$ & Vm & $\mathrm{Dm}$ & Am & $\mathrm{Fm}$ & $\mathrm{Cm}$ & RWL & LI & LI Terpilih & Keterangan \\
\hline \multirow{2}{*}{1 (Kiri) } & Origin & 23 & 1 & 0.976 & 0.851 & 1 & 0.91 & 0.9 & 15.646 & 1.278 & \multirow{2}{*}{1.549} & \multirow{2}{*}{ Mungkin Berisiko } \\
\hline & Destination & 23 & 0.862 & 0.934 & 0.851 & 1 & 0.91 & 0.9 & 12.908 & 1.549 & & \\
\hline \multirow{2}{*}{1 (Kanan) } & Origin & 23 & 0.781 & 0.976 & 0.851 & 1 & 0.91 & 0.9 & 12.224 & 1.636 & \multirow{2}{*}{1.636} & \multirow{2}{*}{ Mungkin Berisiko } \\
\hline & Destination & 23 & 0.862 & 0.913 & 0.851 & 1 & 0.91 & 0.9 & 12.617 & 1.585 & & \\
\hline \multirow{2}{*}{3 (Kiri) } & Origin & 23 & 0.862 & 0.934 & 0.851 & 1 & 0.91 & 0.9 & 12.908 & 1.549 & \multirow{2}{*}{2.580} & \multirow{2}{*}{ Mungkin Berisiko } \\
\hline & Destination & 23 & 0.610 & 0.793 & 0.851 & 1 & 0.91 & 0.9 & 7.752 & 2.580 & & \\
\hline \multirow{2}{*}{3 (Kanan) } & Origin & 23 & 0.862 & 0.913 & 0.851 & 1 & 0.91 & 0.9 & 12.617 & 1.585 & \multirow{2}{*}{2.468} & \multirow{2}{*}{ Mungkin Berisiko } \\
\hline & Destination & 23 & 0.610 & 0.829 & 0.851 & 1 & 0.91 & 0.9 & 8.103 & 2.468 & & \\
\hline
\end{tabular}

\section{Risiko Cedera dengan Perhitungan MPL}

Tujuan dari perhitungan AL dan MPL ini adalah untuk mengetahui bagaimana pengaruh gaya tekan yang diterima L5/S1 yang mengakibatkan timbulnya risiko cedera tulang belakang. Apabila nilai gaya tekan (Fc) lebih besar dari batas maksimum yang ditentukan oleh National Instiute of Safety and Health (NIOSH) [4] yaitu sebesar 
6400N maka pekerjaan tersebut sangat berbahaya. Nilai MPL yang akan dinilai dilakukan pada pekerjaan mengangkat galon dari mobil (Aktivitas 1) dan menurunkan galon (Aktivitas 3) saja. Untuk aktivitas berjalan ke dalam toko tidak dinilai karena tidak adanya perpindahan ketinggian benda saat pekerja memindahkan galon air. Dari tabel perhitungan nilai AL dan MPL, diketahui bahwa beban yang diangkat oleh pekerja lebih berat daripada nilai AL dan lebih kecil daripada MPL sehingga pekerjaan tersebut mungkin mengandung risiko cedera tulang belakang atau MSDs.

\section{Grafik Denyut Jantung dan Perhitungan Waktu Istirahat}

Pengukuran denyut jantung merupakan salah satu alat untuk mengetahui beban kerja.Pembuatan grafik denyut jantung untuk mengetahui bagaimana perubahan denyut jantung pekerja yang terjadi selama pekerja melakukan pekerjaannya yaitu mengangkat galon air. Denyut jantung pekerja diukur sebelum, selama dan setelah beraktivitas (Gambar 2). Hal ini dikarenakan peneliti ingin mengetahui berapa waktu yang dibutuhkan pekerja untuk mencapai denyut jantung awal kemudian akan dibandingkan dengan waktu istirahat yang akan dihitung menurut teori.

Tabel 3. Perhitungan AL dan MPL

\begin{tabular}{|c|c|c|c|c|c|c|c|c|c|c|}
\hline Aktivitas & Bagian & Kondisi & $\mathrm{H}$ & V & D & $\mathrm{F}$ & Fmax & $\mathrm{AL}$ & MPL & Keterangan \\
\hline \multirow{4}{*}{1} & \multirow{2}{*}{ Kanan } & Origin & 32 & 77 & 145 & 2 & 18 & 13.073 & 39.220 & Mungkin Berisiko \\
\hline & & Destination & 29 & 98 & 145 & 2 & 18 & 13.204 & 39.613 & Mungkin Berisiko \\
\hline & \multirow{2}{*}{ Kiri } & Origin & 22 & 77 & 145 & 2 & 18 & 19.016 & 57.048 & Mungkin Berisiko \\
\hline & & Destination & 29 & 91 & 145 & 2 & 18 & 13.612 & 40.835 & Mungkin Berisiko \\
\hline \multirow{4}{*}{3} & \multirow{2}{*}{ Kanan } & Origin & 29 & 98 & 145 & 2 & 18 & 13.204 & 39.613 & Mungkin Berisiko \\
\hline & & Destination & 41 & 12 & 145 & 2 & 15 & 12.889 & 38.666 & Mungkin Berisiko \\
\hline & \multirow{2}{*}{ Kiri } & Origin & 29 & 91 & 145 & 2 & 18 & 13.612 & 40.835 & Mungkin Berisiko \\
\hline & & Destination & 41 & 0 & 145 & 2 & 15 & 13.383 & 40.148 & Mungkin Berisiko \\
\hline
\end{tabular}

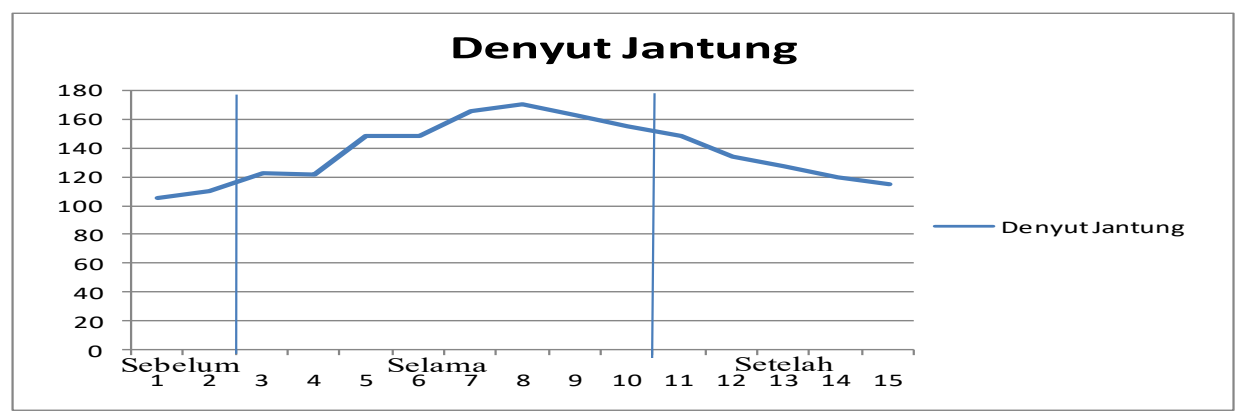

Gambar 2. Grafik denyut jantung sebelum, selama dan setelah aktivitas

Dari hasil perhitungan didapatkan bahwa waktu istirahat yang diperlukan oleh pekerja untuk mencapai kondisi denyut jantung sebelum bekerja adalah 10 menit (secara teoritis). Waktu istirahat aktual pekerja sekarang adalah 5 sampai 7 menit apabila langsung menuju toko berikutnya yang berarti bahwa waktu istirahat pekerja kurang untuk mencapai kondisi aktual.Tetapi apabila pekerja harus kembali terlebih dahulu ke pabrik maka waktu istirahat yang ada adalah 25 menit sehingga waktu untuk mencapai recovery sudah cukup. Kebanyakan pekerja langsung menuju ke toko lain untuk mendistribusikan galon air sehingga waktu istirahat yang diusulkan dapat digunakan agar pekerja terhindar dari rasa kelelahan atau fatique yang dapat menjadi salah satu faktor penyebab timbulnya risiko cedera tulang belakang.

Aktivitas pengangkatan galon yang dilakukan oleh pekerja dinilai bermasalah dan berpotensi menyebabkan cedera tulang belakang baik secara subjektif maupun secara objektif dari segi biomekanika dan fisiologi. Penilaian secara subjektif didapatkan dari hasil kuesioner Nordic Body Map yang telah diisi sendiri oleh pekerja berdasarkan keluhan rasa sakit yang dirasakannya selama melakukan aktivitas pengangkatan galon air. Sedangkan penilaian secara objektif dilihat dari hasil pengolahan data dengan menggunakan metode REBA (Rapid Entire Body Assesment), RWL (Recommended Weight Limit) dan MPL (Maximum Permissible Limit). Penilaian secara fisiologi dapat dilihat dari hasil pengolahan data denyut jantung yang akan dihitung berapa lama waktu istirahat ideal yang dibutuhkan oleh pekerja agar terhindar dari risiko cedera tulang belakang. Adapun hasil rangkuman dari pengolahan ketiga metode tersebut dapat dilihat pada Tabel 4. 
Tabel 4. Tabel Rangkuman hasil REBA, RWL dan MPL

\begin{tabular}{|c|c|c|c|c|c|c|c|c|c|}
\hline \multirow[b]{2}{*}{ Aktivitas } & \multirow[b]{2}{*}{ Kegiatan } & \multicolumn{3}{|r|}{ REBA } & \multicolumn{2}{|r|}{ RWL } & \multicolumn{3}{|c|}{ MPL } \\
\hline & & $\begin{array}{l}\text { Final } \\
\text { Score }\end{array}$ & $\begin{array}{l}\text { Tingkat } \\
\text { Resiko }\end{array}$ & Keterangan & $\begin{array}{l}\text { Lifting } \\
\text { Index }\end{array}$ & Tingkat Resiko & $\begin{array}{c}\text { Batas } \\
\text { Angkat } \\
\text { Minimum }\end{array}$ & $\begin{array}{c}\text { Batas } \\
\text { Angkat } \\
\text { Maksimum }\end{array}$ & Tingkat Resiko \\
\hline 1 & $\begin{array}{l}\text { Mengangkat galon } \\
\text { air dari mobil }\end{array}$ & 4 & $\begin{array}{c}\text { Resiko } \\
\text { Menengah }\end{array}$ & $\begin{array}{l}\text { Butuh analisis dan perbaikan } \\
\text { segera }\end{array}$ & 1.640 & $\begin{array}{l}\text { Mungkin } \\
\text { Beresiko }\end{array}$ & 13.389 & 40.167 & $\begin{array}{l}\text { Mungkin } \\
\text { Beresiko }\end{array}$ \\
\hline 2 & $\begin{array}{l}\text { Berjalan menuju } \\
\text { bagian dalam toko }\end{array}$ & 5 & $\begin{array}{c}\text { Resiko } \\
\text { Menengah }\end{array}$ & $\begin{array}{l}\text { Butuh a nalisis dan perbaikan } \\
\text { segera }\end{array}$ & - & - & - & - & - \\
\hline 3 & $\begin{array}{l}\text { Menurunkan galon } \\
\text { air }\end{array}$ & 8 & $\begin{array}{l}\text { Resiko } \\
\text { Tinggi }\end{array}$ & $\begin{array}{c}\text { Perlu analisis dan } \\
\text { implementasi perbaikan }\end{array}$ & 2.640 & $\begin{array}{l}\text { Mungkin } \\
\text { Beresiko }\end{array}$ & 12.932 & 38.796 & $\begin{array}{l}\text { Mungkin } \\
\text { Beresiko }\end{array}$ \\
\hline
\end{tabular}

Nilai konsumsi energi (KE) dan waktu istirahat (R) dilakukan untuk mengetahui berapa konsumsi energi rata-rata yang dibutuhkan untuk bekerja dalam satuan Kkal per menit. Setelah menghitung energi sebelum dan sesudah aktivitas maka kita dapat menghitung besar konsumsi energi rata-rata dengan mengurangkan energi sesudah aktivitas dengan energi sebelum aktivitas. Kita juga dapat mengetahui berapa waktu yang dibutuhkan pekerja untuk beristirahat secara teoritis $(\mathrm{R})$ dengan persamaan sebagai berikut.

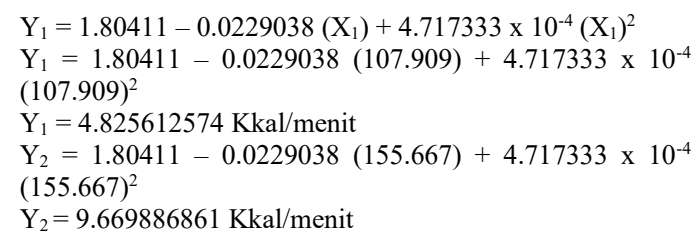

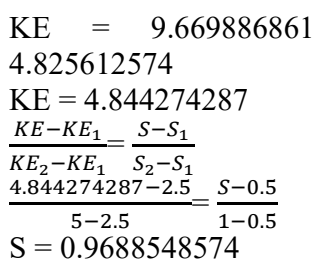

$$
\begin{aligned}
& \mathrm{R}=\frac{T(K E-S)}{K E-1,5} \\
& \mathrm{R}=\frac{8(4,844274287-0,9688548574)}{4,844274287-1,5} \\
& \mathrm{R}=9270577942 \text { menit } \\
& \mathrm{R} \approx 10 \text { menit }
\end{aligned}
$$

$X_{1}=$ Kecepatan denyut jantung sebelum aktivitas (denyut per menit) $\mathrm{X}_{2}=$ Kecepatan denyut jantung setelah aktivitas (denyut per menit)

$\mathrm{Y}_{1}=$ Energi sebelum aktivitas (Kkal per menit)

$\mathrm{Y}_{2}=$ Energi sesudah aktivitas (Kkal per menit)

\author{
$\mathrm{KE}=$ Konsumsi energi rata-rata untuk bekerja (Kkal per menit) \\ $\mathrm{R}=$ Istirahat yang dibutuhkan dalam menit \\ $\mathrm{T}=$ Total waktu kerja dalam menit \\ $\mathrm{S}=$ Pengeluaran energi rata-rata yang direkomendasikan \\ $\mathrm{KE}_{1}$ dan $\mathrm{KE}_{2}$ adalah batas antara $\mathrm{KE}$.
}

Berdasarkan tabel kebutuhan energi untuk setiap pekerjaan [2] dapat dilihat bahwa pekerjaan yang dilakukan oleh pekerja berada dalam klasifikasi pekerjaan yang sangat berat karena denyut jantung pekerja mencapai 171 denyut/menit. Selain itu berdasarkan perhitungan waktu istirahat yang diperlukan bagi pekerja untuk mencapai denyut jantung sebelum bekerja pada kondisi awal yaitu 10 menit sedangkan waktu istirahat aktual pekerja yaitu 5 menit sampai 7 menit waktu untuk mencapai toko berikutnya lagi. Dari klasifikasi pekerjaan dan perhitungan waktu istirahat dapat dikatakan bahwa pekerjaan tersebut merupakan salah satu pekerjaan yang sangat berat dan mengandung risiko cedera tulang belakang saat bekerja dikarenakan pekerjaan tersebut cukup berat dan memiliki waktu istirahat yang kurang.

\section{a. Perancangan}

Hasil perancangan dapat dikatakan baik apabila bisa mengurangi risiko cedera yang akan dialami oleh pekerja. Terdapat 2 alternatif usulan material handling yaitu troli konveyor dan handtruck. Adapun ukuran dimensi yang digunakan dalam perancangan ini mengacu pada data anthropometri yang digunakan pada buku referensi "Ergonomi: Konsep Dasar dan Aplikasinya" Nurmianto [3].

\section{Troli konveyor (Alternatif 1)}

Troli konveyor ini difungsikan sebagai alat untuk memindahkan beban dimana konveyor ini dapat diatur ketinggiannya untuk mempermudah pekerja memindahkan beban (galon) ketika melewati jalan yang menanjak. Adapun data dimensi dan gambar material handling yang diusulkan dapat dilihat pada Tabel 5. Panjang troli pada alat material handling adalah $65 \mathrm{~cm}$. Ukuran ini dipertimbangkan karena ukuran diameter satu buah galon $27 \mathrm{~cm}$, sehingga 2 buah galon memiliki total lebar $54 \mathrm{~cm}$. Selain itu pada saat troli konveyor akan disimpan konveyor dapat dilipat ke atas troli sehingga membutuhkan ruang lebih untuk menyimpan konveyor sebesar $11 \mathrm{~cm}$. Lebar troli adalah $87 \mathrm{~cm}$,ukuran ini dipertimbangkan karena ukuran panjang 3 buah galon $51 \mathrm{~cm}$. Selain itu troli juga dapat dipakai untuk menyimpan konveyor di atasnya dengan panjang lipatan konveyor $87 \mathrm{~cm}$ sehingga dipilih ukuran maksimum agar dapat menampung keduanya yaitu $87 \mathrm{~cm}$. Panjang pegangan troli dari permukaan tanah adalah 100,3 cm, ukuran ini dipertimbangkan berdasarkan data anthropometri tinggi siku berdiri pria (persentil 50). Hal ini bertujuan agar pekerja dapat dengan mudah mendorong alat material handling tersebut, karena 
menurut Health Safety Executive [1], posisi mendorong maupun mengangkat yang baik berada di antara pinggul dan bahu. Penggunaan persentil 50 dimaksudkan agar semua orang baik orang berukuran besar maupun orang berukuran kecil tidak memiliki masalah ketika menggunakan alat ini. Diameter pegangan troli adalah 4,5 cm, ukuran ini dipertimbangkan berdasarkan data anthropometri diameter genggaman pria (persentil 5). Hal ini bertujuan agar pekerja dapat menggenggam pegangan dengan nyaman pada saat mendorong troli. Penggunaan pesentil 5 dimaksudkan agar orang dengan diameter genggaman paling kecil dapat menggunakan alat ini dengan nyaman.

Diameter roda adalah $9 \mathrm{~cm}$, alasannya roda dengan diameter $9 \mathrm{~cm}$ akan mampu untuk menahan beban seberat 150 $\mathrm{kg}$. Lebar konveyor adalah $300 \mathrm{~cm}$. Panjang konveyor disesuaikan dengan jarak dari mobil ke bagian dalam toko. Panjang ini dihitung vertikal karena jalan menuju toko dalam kondisi aktual miring atau menanjak ke atas. Panjang konveyor adalah $60 \mathrm{~cm}$. Lebar konveyor ini dipertimbangkan karena panjang roll konveyor berukuran $43 \mathrm{~cm}$, selain itu masih terdapat kaki dan ruang simpan konveyor berukuran $17 \mathrm{~cm}$ sehingga didapat ukuran lebar konveyor $60 \mathrm{~cm}$. Adapun ukuran lebar balok penurun adalah $22 \mathrm{~cm}$. Ukuran balok penurun ini dipertimbangkan karena penulis mengambil sudut $30^{\circ}$ pada penurunan galon ini. Sehingga dapat dilakukan perhitungan sin $30^{\circ}$ dengan panjang sisi tegaknya $11 \mathrm{~cm}$ didapatkan hasil bahwa panjang sisi miringnya sebesar $22 \mathrm{~cm}$. Pemakaian sudut $30^{\circ}$ agar papan penurun galon air lebih landai agar memudahkan operator menurunkan galon air dari atas troli. Material handling yang diusulkan memiliki empat buah roda yang memudahkan beban untuk dipindahkan dari satu tempat ke tempat lainnya dengan mudah. Roda ini juga dilengkapi dengan pengunci yang akan memastikan alat ini tidak akan bergerak pada saat beban dipindahkan ke atas alat ini. Cara pengunci roda ini sangat mudah yaitu dengan menginjak bagian depan pengunci dan roda akan langsung terkunci dan tidak akan bergerak sedangkan untuk membuat roda dapat bergerak lagi tinggal menginjak bagian belakang pengunci.

Tabel 5. Dimensi usulan material handling alternatif 1

\begin{tabular}{|c|c|c|c|c|c|c|c|c|}
\hline No. & Simbol & $\begin{array}{c}\text { Ukuran } \\
(\mathrm{cm})\end{array}$ & Jenis Dimensi & Data yang digunakan & $\begin{array}{l}\text { Ukuran } \\
(\mathrm{cm})\end{array}$ & Persentil (\%) & Data yang digunakan & $\begin{array}{l}\text { Ukuran } \\
(\mathrm{cm})\end{array}$ \\
\hline 1 & A & 65 & Panjang Trolley & Diameter 2 buah galon & 54 & - & Ruang buat menaruh konveyor & 11 \\
\hline 2 & $B$ & 87 & Lebar Trolley & Panjang lipatan konveyor & 87 & - & - & - \\
\hline 3 & C & 100.3 & Tinggi Pegangan Trolley dari permukaan tanah & Tinggi Siku Berdiri (pria) & - & 50 & - & - \\
\hline 4 & $\mathrm{D}$ & 4.5 & Diameter Pegangan Trolley & Genggaman Tangan (pria) & - & 5 & - & - \\
\hline 5 & $\mathrm{E}$ & 9 & Diameter Roda & - & - & - & - & - \\
\hline 6 & $\mathrm{~F}$ & 300 & Lebar Konveyor & $\begin{array}{c}\text { Jarak dari tinggi lantai toko } \\
\text { ke bak mobil box }\end{array}$ & - & & - & - \\
\hline 7 & G & 60 & Panjang Konveyor & Panjang roll & 43 & - & Kaki dan ruang simpan konveyor & 17 \\
\hline 8 & $\mathrm{H}$ & 2 & Tebal Trolley & - & - & - & - & - \\
\hline 9 & I & 1 & Tebal Sisi Trolley & - & - & - & - & - \\
\hline 10 & J & 5 & Tinggi Sisi Trolley & - & - & - & - & - \\
\hline 11 & K & 40 & Panjang Balok Penurunan Galon & $\begin{array}{l}\text { Jarak antara } 2 \text { titik } \\
\text { penyangga conveyor }\end{array}$ & - & - & - & - \\
\hline 12 & L & 22 & Lebar Balok Penurun Galon & \begin{tabular}{|c|} 
Dihitung dari panjang sudut \\
balok ke lantai sebesar 30
\end{tabular} & - & - & - & - \\
\hline
\end{tabular}

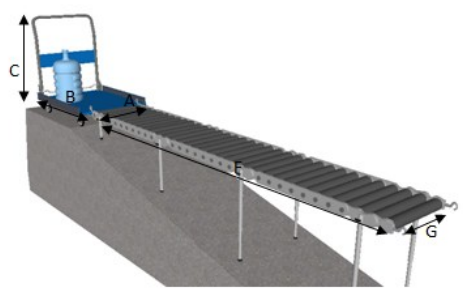

Gambar 3. Usulan Troli Konveyor(Alternatif 1)

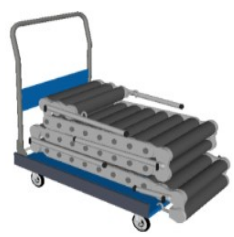

Gambar 5. Troli Konveyor yang dapat dilipat

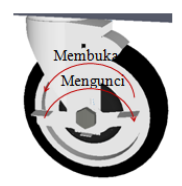

Gambar 6. Pengunci dan pembuka pada roda

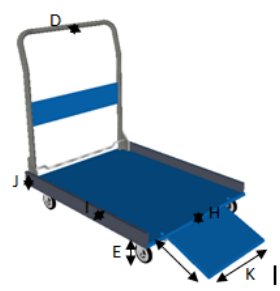

Gambar 4. Gambar Troli

$1 \mathrm{~cm}$

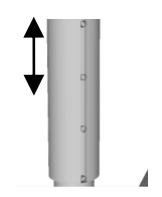

Gambar 7. Pengatur ketinggian kaki konveyor 
Selain itu material handling (alternatif 1) yang diusulkan dapat dipisahkan dari konveyor pada saat digunakan. Proses pemasangan dan pelepasan konveyor dari troli sangat sederhana dengan menggunakan pengait.
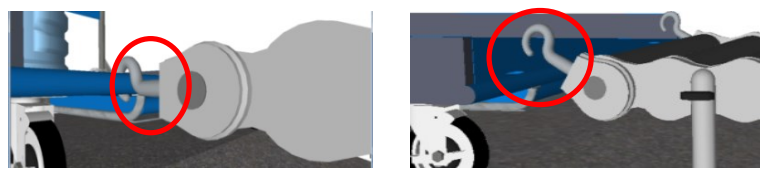

Gambar 8. Pengait terbuka saat troli dan konveyor dipisahkan

Pada konveyor terdapat roll konveyor dengan diameter yang berukuran $5 \mathrm{~cm}$ dan jarak antar roll konveyor sebesar $2 \mathrm{~cm}$. Hal ini dikarenakan roll yang semakin kecil akan semakin mempermudah barang yang akan dipindahkan. Semakin kecil jarak antar roll akan semakin baik tetapi dalam usulan alat material handling ini tetap diberikan jarak dengan tujuan agar lebih memudahkan konveyor pada saat pelipatan. Konveyor pada material handling yang diusulkan memiliki kaki yang dapat diatur ketinggiannya dengan range setiap $1 \mathrm{~cm}$. Cara untuk memasang dan menyimpan kakinya juga sangat sederhana dengan satu pengunci.Untuk menyesuaikan ukuran kaki juga sangat sederhana. Untuk mekanisme pemasangan kaki konveyor dapat dilihat pada Gambar 9 dan Gambar 10.

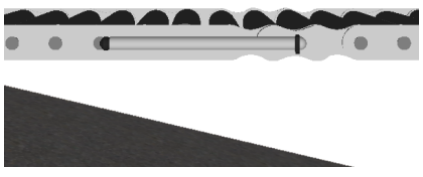

Gambar 9. Posisi kaki konveyor awal

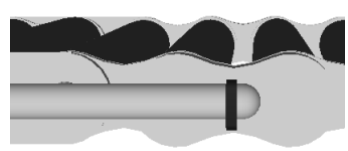

Gambar 10. Pemutaran pengunci kaki konveyor

Ketika hendak memasangkan troli konveyor ke mobil maka mobil harus berada tepat di posisinya yaitu bagian depan tanjakan. Posisi yang tepat ini dapat diperoleh dengan menggunakan bantuan batu yang diletakkan di bagian depan tanjakan sehingga troli konveyor dapat dengan tepat dipasangkan di mobil pengantar galon air.

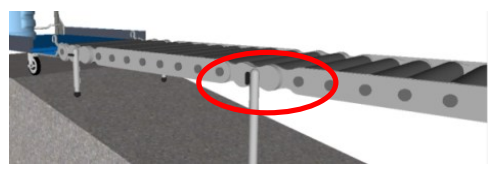

Gambar 11. Posisi kaki konveyor turun saat pengunci dibuka

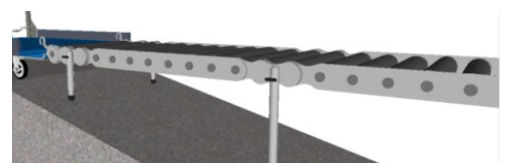

Gambar 12. Posisi pengunci dikembalikan ke kondisi semula

Batu diletakkan sekitar $10 \mathrm{~cm}$ dari tanjakan. Dengan bantuan alat material handling ini, diharapkan dapat mengurangi risiko cedera tulang belakang yang dapat dialami oleh pekerja pada saat melakukan aktivitas pengangkatan galon air.Hal ini dikarenakan dengan bantuan troli konveyor pekerja jadi tidak perlu melakukan kegiatan mengangkat galon air dengan jalan yang menanjak seperti kondisi sebelumnya.

\section{Handtruck (Alternatif 2)}

Perancangan handtruck ini dibuat untuk memudahkan operator dalam membawa galon dari mobil ke toko, baik dalam meminimasi postur yang berisiko maupun maksimasi jumlah beban yang dapat diangkat. Berikut data dimensi dan gambar material handling alternatif 2 yang diusulkan.

Tabel 6. Dimensi usulan material handling alternatif 2

\begin{tabular}{|c|c|c|c|c|c|c|c|}
\hline \multirow[b]{2}{*}{ No. } & \multirow[b]{2}{*}{ Simbol } & \multirow[b]{2}{*}{ Jenis Dimensi } & \multicolumn{3}{|c|}{ Patokan Data } & \multicolumn{2}{|l|}{ Allowance } \\
\hline & & & Data yang digunakan & $\begin{array}{c}\text { Persentil } \\
\text { (\%) }\end{array}$ & $\begin{array}{c}\text { Ukuran } \\
(\mathrm{cm})\end{array}$ & Data yang digunakan & $\begin{array}{c}\text { Ukuran } \\
(\mathrm{cm})\end{array}$ \\
\hline 1 & A & Panjang handtruck & Tinggi Galon & - & 37 & & \\
\hline 2 & $B$ & Lebar handtruck & diameter galon & - & 27 & - & 2 \\
\hline 3 & $\mathrm{C}$ & Tinggi handtruck & Tinggi Bahu Berdiri (Pria) & P5 & 124.7 & & \\
\hline 4 & $\mathrm{D}$ & Diameter Pegangan & Diameter lingkar gengam & P5 & 4.5 & - & - \\
\hline
\end{tabular}

Data antropometri yang dibutuhkan untuk menentukan ukuran tinggi handtruck (sebagai handle) pada posisi berdiri dengan keadaan setimbang adalah tinggi bahu berdiri dengan persentil $5 \%$ pria yaitu $124,7 \mathrm{~cm}$, agar pekerja yang berbadan kurang tinggi tidak akan terganggu kenyamanannya pada saat menjangkau handle handtruck. Dimensi yang lain akan berpatokan pada ukuran dimensi galon air, hal ini dilakukan agar terhindar dari jatuhnya 
galon air pada saat digerakkan handtruck-nya. Model handtruck di desain menggunakan baja agar kuat dan terdapat penahan agar galon air tidak akan jatuh pada saat melewati bidang miring. Pada sisi depan handtruck, terdapat besi penghalang dan pengunci di dekat handle untuk dapat menahan galon air itu agar terhindar dari terjatuh pada saat handtruck di dorong. Handtruck ini dapat memuat 3 galon sekaligus dalam sekali pengantaran, sehingga akan meminimasi waktu pengantaran galon air ke toko " $\mathrm{X}$ ".
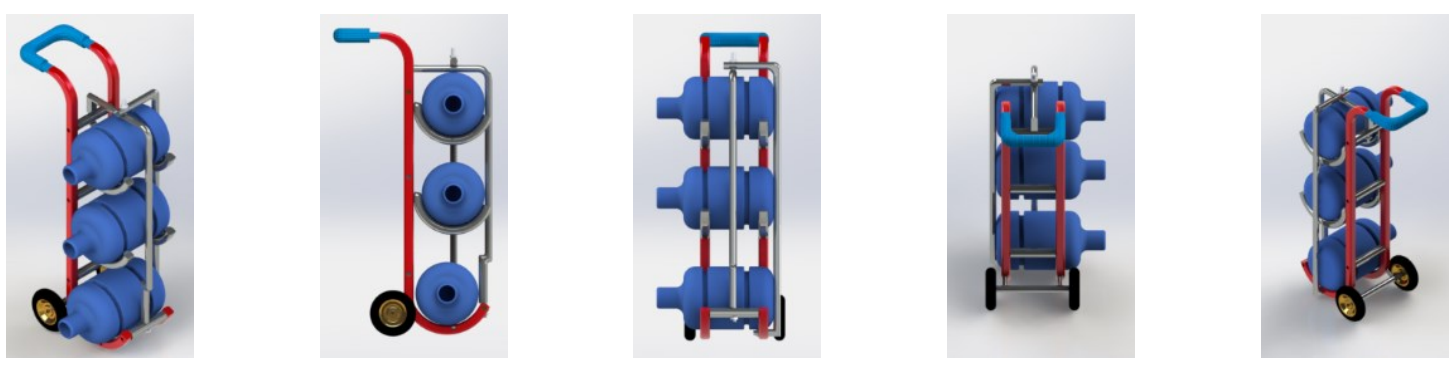

Gambar 13. Handtruck dilihat dari beberapa sisi (alternatif 2)

\section{b. Pemilihan Alternatif}

Untuk menentukan alternatif yang akan digunakan, maka dilakukan concept scoring dengan menggunakan bobot yang sama pada setiap kriteria karena kelima faktor di atas mempunyai tingkat kepentingan yang sama. Kriteria yang digunakan adalah kriteria keamanan, kenyamanan, kesesuaian dengan antropometri, kemudahan, tenaga yang dikeluarkan dan desain rancangan yang fungsional. Dari hasil concept scoring, diperoleh bahwa alternatif 1 memiliki nilai yang paling besar sehingga alternatif 1 terpilih sebagai material handling yang dapat memudahkan pekerjaan operator.

\section{c. Perhitungan REBA Usulan}

Setelah alternatif 1 ditetapkan sebagai alternatif yang layak digunakan sebagai material handling yang akan digunakan oleh toko "X". Maka perlu adanya simulasi dan perhitungan postur REBA usulan dengan menggunakan troli konveyor. Selain postur tubuh pekerja yang pada kondisi sebelumnya yang harus mengangkat galon dengan posisi membungkuk, sekarang tidak harus membungkuk lagi sehingga keluhan sakit tubuh pada beberapa bagian tubuh pekerja dapat berkurang. Troli konveyorjuga membantu pekerja tidak perlu mengangkat galon air tersebut secara manual lagi tetapi hanya mendorong galon air sehingga tenaga yang dikeluarkan juga berkurang. Waktu istirahat yang diperlukan pekerja juga berkurang karena tenaga yang dikeluarkan tidak terlalu besar sehingga waktu untuk mencapai kondisi awal tidak terlalu lama. Postur pekerja usulan ini hanya untuk aktivitas 2 dan aktivitas 3 saja. Hal ini dikarenakan untuk aktivitas 1 merupakan kondisi dimana pekerja mengangkat galon air dari mobil box sehingga tidak dapat diberikan usulan terkait dengan aktivitas 1 tersebut. Selain itu juga untuk aktivitas 2 terdapat sedikit perbedaan dengan aktivitas awal. Sebelumnya aktivitas 2 merupakan postur tubuh pekerja saat berjalan menuju bagian dalam toko, sedangkan dalam usulan ini menjadi postur tubuh pekerja pada saat mendorong galon air melalui konveyor.

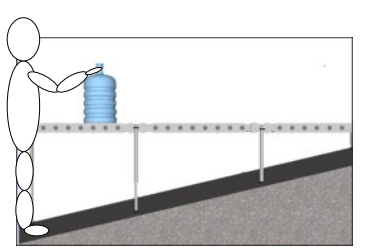

Gambar 14. Postur tubuh usulan aktivitas 2 (berjalan menuju bagian dalam toko)

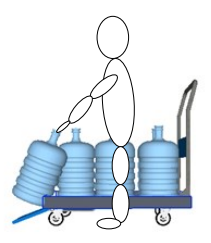

Gambar 15. Postur tubuh usulan aktivitas 3 (menurunkan galon air)

Berdasarkan result simulasi dari gambar diatas, maka diketahui final score REBA adalah 3 dengan keterangan level risiko rendah dan perbaikan mungkin dibutuhkan. Berikut adalah rangkuman hasil akhir dari final score postur tubuh pekerja usulan yang didapatkan dengan metode REBA serta keputusan tindakan yang perlu dilakukan terkait dengan tingkat risiko yang telah didapatkan.

Tabel 7. Rangkuman final score REBA usulan

\begin{tabular}{|c|c|c|c|c|}
\hline Aktivitas & Kegiatan & Final Score & Tingkat Risiko & Keterangan \\
\hline 1 & Mengangkat galon air dari mobil & - & - & - \\
\hline 2 & Berjalan menuju bagian dalam toko & 3 & Rendah & Perbaikan mungkin diperlukan \\
\hline 3 & Menurunkan galon air & 3 & Rendah & Perbaikan mungkin diperlukan \\
\hline
\end{tabular}


Terjadinya penurunan nilai score dapat dilihat juga pada perbedaan sudut tubuh pekerja setelah menggunakan troli konveyor sehingga pekerja tidak perlu terlalu membungkuk dan rasa sakit pada beberapa bagian tubuh dapat dikurangi.

\section{Kesimpulan dan Saran}

Tingkat risiko tinggi disebabkan karena pada proses penurunan galon air dilakukan pada posisi yang sangat membungkuk yang mengakibatkan semakin tingginya risiko cedera tulang belakang yang akan dialami oleh pekerja. Posisi yang sangat membungkuk menyebabkan pekerja mengalami sakit di bagian punggung dan pinggang. Hal ini sesuai dengan keluhan pekerja yang di dapat dari Kuesioner Nordic Body Map. Dapat dilihat bahwa terjadi penurunan risiko cedera tulang belakang yang cukup signifikan. Tidak ada lagi tingkat risiko tinggi yang dialami oleh pekerja. Tingkat risiko menengah juga hanya terdapat pada aktivitas 1 dimana itu merupakan kondisi yang tidak dapat diubah lagi karena merupakan kondisi pada saat pekerja mengangkat galon air dari mobil. Dengan adanya alat bantu berupa troli konveyor yang membantu pekerja tidak perlu untuk mengangkat galon air menuju toko sehingga postur tubuh pekerja dapat menjadi lebih baik. Pekerja juga tidak perlu membungkuk pada saat meletakkan galon air ke tempat tujuan. Metode RWL dan MPL tidak dipergunakan dalam perhitungan usulan karena pada alat bantu usulan sudah membantu pekerja agar tidak perlu mengangkat galon air tersebut dan pekerja hanya perlu mendorong galon air tersebut saja sehingga kedua metode tersebut tidak dapat digunakan kembali. Waktu istirahat yang diperlukan oleh pekerja untuk mencapai kondisi semula adalah 10 menit (secara teoritis), dengan adanya alat bantu yang diusulkan maka pekerja tidak perlu untuk mengeluarkan tenaga sebesar kondisi awal yaitu mengangkat galon secara manual dan melewati jalan yang menanjak ke atas, sehingga dengan waktu istirahat yang sekarang pekerja cukup untuk kembali ke kondisi semula.

\section{Daftar Pustaka}

[1] HSE, 2012, Manual material handling at work: a brief guide, Health Safety Executive [http://www.hse.gov.uk/pubns/indg143.pdf]

[2] Kroemer, K.H.E., Kroemer, H.B., \& Kroemer , K.E., 2001, Ergonomics : How to Design for Ease adn Efficiency, New Jersey, Prentice-Hall.

[3] Nurmianto, E. 1996. Ergonomi Konsep Dasar dan Aplikasinya. PT. Guna Widya

[4] NIOSH, 1981, National Institute for Occupational Safety and Health : A Work Practices Guide for Manual Lifting. Technical Report No. 81-122 (Cincinnati : US Department of Health and Human Services (NIOSH))

[5] Tarwaka, 2010, Ergonomi Industri, Dasar-dasar Pengetahuan Ergonomi dan Aplikasi di Tempat Kerja, Harapan Press, Solo. 